\title{
Suprapubic cystostomy: a bizarre complication of catheter migration causing ureteric obstruction
}

\author{
Dr. Pankaj P. Dangle, MD, Mch; Dr. James Tycast, MD; Dr. Evalynn Vasquez, MD; Dr. Brian Geary, MD; \\ Dr. Micheal Chehval, MD
}

\begin{abstract}
Suprapubic catheters are used routinely for bladder drainage; however, complications are commonly reported. These complications could be attributed to surgical technique or the catheter itself. Complications related to surgical technique can be controlled and reduced, but catheter-related complications are unavoidable and unpredictable. We report a rare catheter-related complication leading to obstruction of the ureter in a solitary kidney in a patient with neurogenic bladder and voiding dysfunction managed with suprapubic catheter drainage.
\end{abstract}

Can Urol Assoc J 2010;4(5):E127-128

\section{Introduction}

Suprapubic catheter drainage is frequently employed for the management of neurogenic bladder with voiding dysfunction. Although it is a safe procedure, multiple intra- and postoperative complications, such as infection, bleeding, and obstruction, are commonly reported. ${ }^{1}$ Less frequent complications, such as expulsion through bladder, bowel perforation, entero-cutaneous fistula, knotting of the catheter and catheter migration in a gaping ureter, are also reported. ${ }^{2-8}$ We report another unusual complication of migration of suprapubic catheter into a previously normal non-gaping intramural ureteral orifice of a solitary kidney.

\section{Case history}

A 50-year-old female with neurogenic bladder secondary to multiple sclerosis managed with a chronic suprapubic catheter for 6 months was admitted with acute exacerbation of multiple sclerosis and symptoms of left-sided pyelonephritis. On admission, the patient was treated conservatively. Further investigations revealed left-sided hydronephrosis without hydroureter, and it was determined that patient had a symptomatic left ureteropelvic junction (UPJ) obstruction (Fig. 1). The diagnosis was confirmed on renal scan which demonstrated $t$ 1 $1 / 2$ time of 23 minutes with delayed excretion.
The patient had a significant past medical history of right radical nephrectomy for Wilm's tumour at childhood. The hypercontractile neurogenic bladder was simultaneously treated with anticholinergic in the form of oxybutynin. After the initial presentation and diagnosis of the UPJ obstruction, the patient was treated with ureteric stent in view of pain and solitary functioning kidney at which time the ureteric orifice appeared to be normal and non-gaping. The patient was scheduled for an elective open pyeloplasty. She presented ( 2 weeks prior to the scheduled surgery) with a sudden increased left abdominal pain and decreased urine output from the suprapubic tube for 24 hours. The patient underwent a computed tomography (CT) of the abdomen and pelvis, which revealed increased hydronephrosis and a newly detected hydroureter compared with a previous CT scan performed 6 months prior to the current episode (Fig. 2 ). The pelvic scan revealed what appeared to be a migrated suprapubic catheter tube into left ureteral orifice and ureter. Due to findings on the CT scan and the patient's symptoms, the situation was treated as a solitary obstructed kidney, the suprapubic catheter (18 French) was changed under aseptic precautions to drain $250 \mathrm{~mL}$ of clear urine. Subsequently, the patient's pain resolved and she was sent home on prophylactic antibiotics. The patient then underwent an uncomplicated open left Anderson-Hynes pyeloplasty with complete resolution of left renal pain. During the surgery, the ureter appeared non-dilated without any crossing vessel at the UPJ.

\section{Discussion}

Suprapubic cystostomy catheter drainage is a well-established procedure for managing neurogenic bladder with voiding dysfunction. Multiple commonly observed complications, such as bacteriuria, bleeding, and bladder calculi, are reported. ${ }^{9}$ Based on a meta-analysis comparing suprapubic catheter tube versus transurethral catheter drainage, the suprapubic route is more acceptable to patients and has reduced microbiological complications. ${ }^{10}$

Currently, appropriate placement of a suprapubic tube can be confirmed cystoscopically. Singh and colleagues reported a case of left pyelonephritis secondary to cath- 


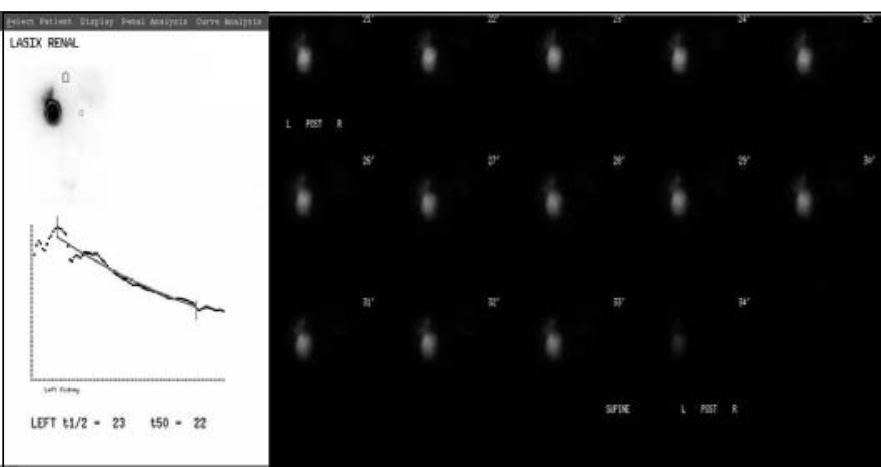

Fig 1. Lasix renograms demonstrating $t \frac{1}{2}$ of 23 minutes with delayed excretion, explicitly demonstrated in the excretory films with excretion beyond 33 minutes.

eter migration in a young male with a suprapubic catheter inserted for traumatic urethral stricture. Cystographic evaluation revealed contrast entering the left ureter with bilateral hydronephrosis. The author hypothesized the possibility of migration of catheter in a gaping ureter with bilateral hydronephrosis. ${ }^{8}$ Similarly, Parikh and colleagues reported a case of urinary retention secondary to suprapubic catheter migration into the prostatic urethra.

In our case, the patient had a neurogenic bladder secondary to multiple sclerosis managed with a suprapubic catheter and presented with catheter migration into left ureteral orifice leading to left hydronephrosis and obstructive uropathy. This is hypothesized based on the new onset left ureteral dilation compared to previous CT scans. The presence of neurogenic bladder could lead to detrussor over activity leading to migration of the catheter tip into the ureteral orifice. Since the patient had a solitary kidney, diagnosing such a condition is crucial for immediate relief to the obstructed kidney.

\section{Conclusion}

In patients with neurogenic bladder with voiding dysfunction managed with suprapubic cystostomy, obstructive uropathy in a solitary functioning kidney should raise the suspicion of a migrated catheter into the ureteral orifice.

Department of Urology, Saint Louis University Hospital, Saint Lovis, MO

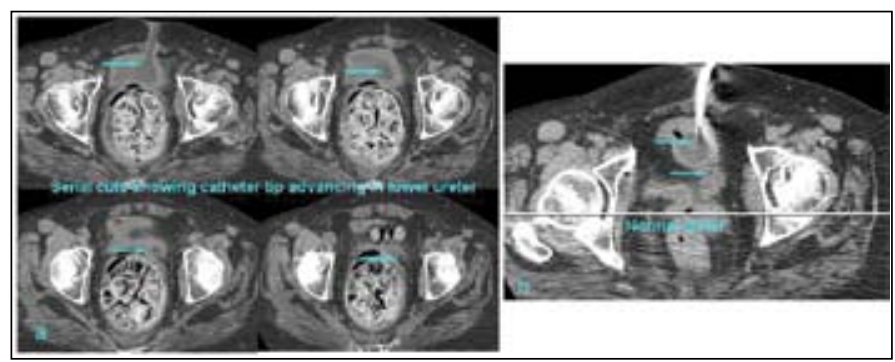

Fig 2. Computed tomography (CT) demonstrating the catheter migration in serial cuts as the catheter is seen in all sections with dilated ureter (a) compared to the nondilated ureter in CT scan done 6 months prior to the current scan (b).

Competing interests: None declared.

This paper has been peer-reviewed.

\section{References}

1. Ahluwalia RS, Johal N, Kouriefs C, et al. The surgical risk of suprapubic catheter insertion and long-term sequelae. Ann R Coll Surg Engl 2006;88:210-3.

2. Vaidyanathan S, Hughes PL, Soni BM. Unusual complication of suprapubic cystostomy in a male patient with tetraplegia: traction on Foley catheter leading to extrusion of Foley balloon from urinary bladder and suprapubic urinary fistula-importance of securely anchoring suprapubic catheter with adhesive tape or BioDerm tube holder. ScientificWorldJournal 2007;7:1575-8.

3. Vaidyanathan S, Hughes PL, Soni BM, et al. Hourglass urinary bladder in a spinal cord injury patient unusual late complication of suprapubic cystostomy: a case report. Cases J 2009;2:6866.

4. Ananthakrishnan K, Ayyathurai R, Chiran JK, et al. An unusual complication of suprapubic catheter insertion. ScientificWorldJournal 2006;6:2433-5.

5. Ahmed SJ, Mehta A, Rimington P. Delayed bowel perforation following suprapubic catheter insertion. BMC Urol 2004;4:16.

6. Farook SA, Kariholu U, Kousidis G, et al. Not to knot a catheter. Case report of the knotting of a suprapubic catheter. ScientificWorldJournal 2007;7:1004-6.

7. Parikh AM, Chapple CR. Suprapubic catheter-an unusual cause of acute retention. Br J Urol 1993;71:494-5.

8. Singh DR, Sailo L, Abraham NB, et al. An unusal complication of percutaneous suprapubic cystostomy. Ind J Urol 2001;2:179-80.

9. Katsumi HK, Kalisvaart JF, Ronningen LD, et al. Urethral versus suprapubic catheter: choosing the best bladder management for male spinal cord injury patients with indwelling catheters. Spinal Cord 2010;48:325-9.

10. McPhail MJ, Abu-Hilal M, Johnson CD. A meta-analysis comparing suprapubic and transurethral catheterization for bladder drainage after abdominal surgery. Br I Surg 2006;93:1038-44.

Correspondence: Dr. Pankaj P. Dangle, Department of Urology, Saint Louis University Hospital, 3635 Vista At Grand Blvd, Saint Lovis, M0 63110; pankajdangle@gmail.com 